\title{
Modeling of Solar/Hydrogen/DEGS Hybrid System for Stand Alone Applications of a Large Store
}

\author{
Won-Pyo Hong ${ }^{\star}$
}

\begin{abstract}
The market for distributed power generation based on renewable energy is increasing, particularly for standalone mini-grid applications in developing countries with limited energy resources. Stand-alone power systems (SAPS) are of special interest combined with renewable energy design in areas not connected to the electric grid. Traditionally, such systems have been powered by diesel engine generator sets (DEGS), but also hybrid systems with photovoltaic and/or wind energy conversion systems (WECS) are becoming quite common nowadays. Hybrid energy systems can now be used to generate energy consumed in remote areas and stand-alone microgrids. This paper describes the design, simulation and feasibility study of a hybrid energy system for a stand-alone power system. A simulated model is developed to investigate the design and performance of stand-alone hydrogen renewable energy systems. The analysis presented here is based on transient system simulation program (TRNSYS) with realistic ventilation load of a large store. Design of a hybrid energy system is site specific and depends on the resources available and the load demand.
\end{abstract}

Key Words : Hydrogen Hybrid Energy System, Diesel Engine Generator Sets (DEGS), TRNSYS, Renewable Energy Sources (RES), Fuel Cell (FC), Electrolyzer, Hydrogen Storage Tank

\section{Introduction}

Electrical energy demand is greater than ever before. Rising concerns about the effects of global warming and declining fossil fuel stocks have led to

* Main author : Dept. of Building \& Plant Engineering, Hanbat National University, Korea

Tel : 042-821-1179, Fax : 042-821-1175

E-mail : wphong@hanbat.ac.kr

Date of submit:2013. 8. 6

First assessment : 2013. 8. 17

Completion of assessment : 2013. 10. 1 increased interest in renewable energy sources (RES). From a Danish case point of view, a 100\% renewable energy supply based on domestic resources is possible, although the design of such a system is a very complex process [1].

Solar energy is inexhaustible, site-dependent, clean (does not produce emissions that contribute to the greenhouse effect), and a potential source of renewable energy. Although solar energy is enormous, a PV-driven power system is still an expensive option [2]. PV systems have the 
advantage of minimum maintenance and easy expansion to meet growing energy needs. However, the power generated by a PV system is highly dependent on weather conditions. In addition, it is difficult to store the power generated by PV panels for future use. To overcome these issues, a PV system can be integrated with other alternative power sources and/or storage systems, such as an electrolyzer, hydrogen storage tank, or fuel cell (FC) system.

In future energy systems such as for remote areas and small scale Microgrids for office buildings, a DER including microturbines and diesel gensets will be used to generate hydrogen, and power demand might be satisfied using RES and FC in hybrid topologies since the hydrogen economy is one vision of the future. A DER such as PV cells and wind turbines can be $\mathrm{CO}^{-}$operated with $\mathrm{FCs}$ in various stand-alone and grid-connected systems [3].

Diesel engine driven generators are the most common electrical energy production schemes in small and medium size power applications. This is because diesel generators are widely available in a broad range from $1 \mathrm{~kW}$ to several hundred kilowatts and there is decades of experience in their operation, maintenance and control [4-6]. Stand-alone diesel gensets (relatively inexpensive to purchase) are generally expensive to operate and maintain especially at low load levels. Energy supply systems based on RES require energy storage because of their fluctuation and the insufficient certainty of supply. An established way of storage is the use of a diesel system. Hydrogen is often referred to as the energy carrier of the future because it can be used to store intermittent RES such as solar and wind energy. Hydrogen produced from RES is absolutely emission free and can be produced locally, thus increasing security of power supply and contributing to energy independence of communities. The idea of creating sustainable energy systems has led over the past decade to several hydrogen energy demonstration projects around the world. Various energy sources (wind, solar, diesel generator) and storage systems (battery, electrolyzer hydrogen tank) were normally considered in such analysis [8-9]. The main motivation for applying hydrogen technology in remote areas is the notion that locally produced renewable hydrogen will be able to compete with traditional fossil fuels (e.g., diesel) sooner at these sites than in more densely populated areas. The situation today is that remote communities are already experiencing relatively high fuel costs. Remote areas with favorable solar power are therefore logical targets for PV energy-based hydrogen systems. Studying the feasibility of adding hydrogen systems to the locations considered requires optimizing the size and number of the system components. Many different size possibilities and topologies configurations must be determined. For example, the size of the PV system, electrolyzer, hydrogen storage tank, fuel cell, and secondary batteries must be determined to ensure that the system is able to meet the required load at the lowest possible cost [9]. The energy performance analysis of a large scale store using a dynamic thermal analysis simulation program has already been performed for analyzing dynamic load [10]. The weather data of the Daejeon area and practical measuring load data of the L large store located in Daejeon City is used in this paper. To maintain the proper space heating, cooling, lighting and ventilating in an indoor environment, the ventilation load data of the $\mathrm{L}$ large store also are used for a simulation of the hydrogen hybrid energy system.

The paper investigates the TRNSYS dynamic models of the components of integrated hydrogen hybrid energy systems such as a PV, FC, 
electrolyzer, hydrogen storage tank, diesel generation system and converter system. The main objective of this study is to evaluate the energy performance of hydrogen hybrid energy systems for stand-alone applications using actual data of the large $\mathrm{L}$ store ventilation loads.

\section{Model System Configuration solar-hydrogen system}

The complete TRNSYS analysis model of an integrated hybrid energy system for stand-alone application to be simulated in this study is shown schematically in Fig. 1. Table 1 illustrates the components of the fuel cell system to be implemented in TRNSYS. It consists of a PV cell array, an electrolyzer, a hydrogen storage tank, a fuel cell, electrical converters/inverters (DC/DC, $\mathrm{DC} / \mathrm{AC}$, and MPPT maximum power point tracker), and loads (electrical and thermal). A brief description of each of the system components is given.

\subsection{Overview of Program}

TRNSYS is a transient systems simulation program with a modular structure. The TRNSYS simulation tool was used to construct the models; TRNSYS was chosen because it already included hydrogen components model (HYDROGRMS [11]) that adapted to the need of the study. The standard TRNSYS library includes many of the components commonly found in thermal and electrical renewable energy systems, as well as component routines to handle input of weather data or other time-dependent forcing functions. The modular structure of TRNSYS gives the program the desired flexibility, as it facilitates for the addition of mathematical models not included in the standard library. The program is well suited to perform detailed analyses of systems whose behavior is dependent on the passage of time [12]. TRNSYS simulates a photovoltaic system with hydrogen as the storage medium. The photovoltaic hydrogen system has a photovoltaic array with an optional maximum power point tracker that supplies electrical energy to the system [13]. This electrical energy supplies the current energy demand, the battery or the electrolyzer with energy. The first priority is the energy demand. If there is more energy supplied than needed, the battery will be charged to a certain level. After the battery reaches this level, the electrolyzer will be turned on, and the hydrogen produced will be stored in a pressurized tank until needed, probably in winter. The hydrogen will be burned in a fuel cell when the solar system does not supply enough energy (with a converter) to produce electrical energy or optionally burned in a catalytic burner for heat. In addition, a solar thermal system gives heat to cover some of the hot water heating demand. The load is modeled from a ventilation load with a fixed value and will vary depending on what location is chosen for the simulation.

Table 1. The type of fuel cell system in TRNSYS

\begin{tabular}{|c|c|c|}
\hline Component & TRNSYS Type & Contents \\
\hline $\begin{array}{ll}\mathrm{H}_{2} \mathrm{KOH} \\
f \mathrm{H}_{2} \mathrm{O}\end{array}$ & TYPE 173 & Alkaline Fuel Cell (H2/O2) \\
\hline 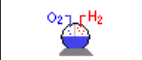 & TYPE 160 & Advanced Alkaline Electrolyzer \\
\hline $\mathrm{H}_{2}$ & TYPE 164 & Compressed Gas Storage \\
\hline Ft & TYPE 167 & Multistage Compressor \\
\hline & TYPE 180 & Silicon Photovoltaic Solar Cell \\
\hline$\therefore$ & TYPE 120 & Diesel Engine Generator System \\
\hline$\theta$ & TYPE 185 & Lead-Acid Battery \\
\hline
\end{tabular}




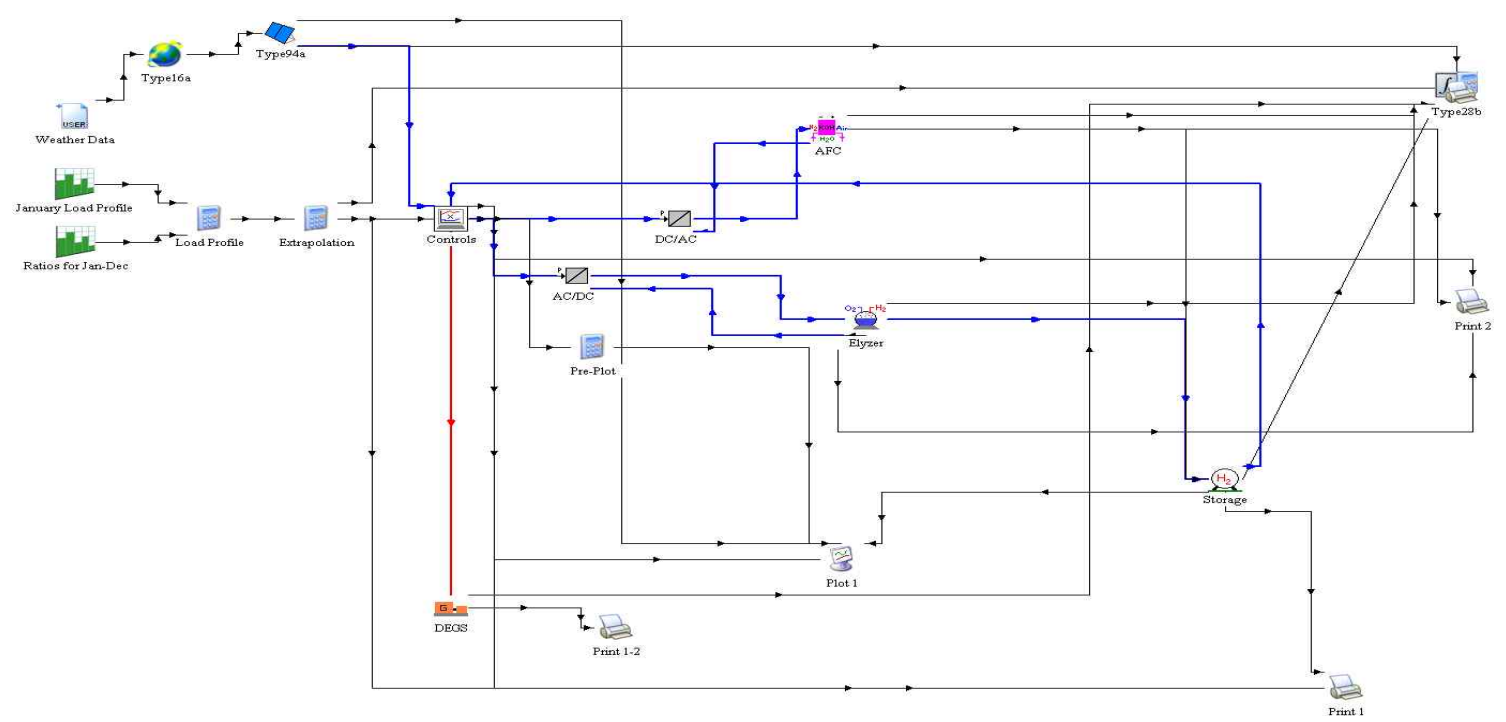

Fig. 1. Detalied TRNSYS analysis model of Solar/Hydrogen/DEGS hybrid System

\subsection{System Simulation}

TRNSYS calculates the state of each component every time through a year of 8760 hours. It is ideal software composed of linked modules, used for modeling such systems consisting of several interconnected components. The components used in the model are:

- Photovoltaic array model with MPPT option,

- Diesel generator model,

- Fuel cell model,

- Electrolyzer model,

- Hydrogen storage tank model,

- Controller,

- Inverter/converter model,

- Scaleable ventilation loads of L store.

\subsubsection{Photovolatic Cells}

The Photovoltaic (PV) cell converts the solar energy directly into electrical energy. With the component subroutine used in this study it is possible to model a single solar cell, a PV module, or an array consisting of many modules. The component uses a single diode model and the cell/module is described by cell parameters. The user may specify the voltage if it is forced upon the cell/module (e.g. by a battery) or if maximum power point tracking is performed. An input control signal serves as an on/off switch of the PV-panel. This can protect the batteries and electrolyzer. The current-voltage equation of PV array model is:

$$
I=I_{L}-I_{o}\left[\exp \left(\frac{q}{\gamma \cdot \kappa \cdot T_{c}}\left(V+I \cdot R_{s}\right)\right)-1\right]
$$

$\mathrm{V}$ Empirical PV curve-fitting parameter

$\mathrm{I}_{\mathrm{L}} \quad$ Module photocurrent

Io Diode reverse saturation current

q Electron charge constant

$\mathrm{k}$ Boltzmann constant

Tc Module temperature

$\mathrm{R}_{\mathrm{S}} \quad$ Module series resistance

The maximum power produced by the PV cell is $P_{\max }=V_{m} \cdot I_{m}=F F \cdot V_{o c} \cdot I_{s c}$ where:

$\mathrm{P}_{\max } \quad$ Maximum Power for the PV

$\mathrm{FF} \quad$ Fill factor

$\mathrm{V}_{\max }$ Voltage at the maximum power point 
$I_{\max } \quad$ Current at the maximum power point

$V_{O C} \quad$ Open-circuit voltage

ISC Short-circuit current

The efficiency of the PV cell is defined as:

$\eta=\frac{P_{\max }}{P_{\text {rad }}}$

where:

$\eta \quad$ Efficiency of a PV cell

$P_{\text {rad }} \quad$ Power of radiation incident upon PV cell

\subsubsection{Diesel Generator Model}

The role of backup diesel generator sets (DEGS) is to provide the auxiliary electrical power required to meet the load. The simulated configuration is a set of diesel engines. The user can adjust the rated power of one engine and the total number of identical engines

The normalized power is defined as:

$$
X=\frac{P_{D E G S}}{P_{D E G S, \text { rated }}}
$$

The electrical efficiency is

$$
\eta_{\text {el }}=P_{{ }^{\circ}} / \rho_{\text {diesel }} \cdot V_{\text {diesel }} \cdot L H V_{\text {diesel }}
$$

The engines are assumed to have a minimal power level, so that selecting large power engines can lead to power being dumped in case the minimal operating power of the engine is larger than the sum of the load and the power used by the electrolyzer.

\subsubsection{Fuel Cell Model}

The fuel cell converts chemical energy to electricity, much like a battery. The difference between a battery and a fuel cell is that the fuel cell does not have any internal storage of chemical energy, but is supplied externally by the fuel. The fuel is pure hydrogen supplied from the hydrogen storage tank. It is possible to use the excess heat from the fuel cell. This heat is not stored and is only used when heat is needed either for hot tap water or space heating. Provided the fuel cell is well insulated, the utilization of excess heat increases the efficiency of the fuel cell from about 50\% to almost 90\% (excluding losses due to parasitic loads and the $\mathrm{dc} / \mathrm{dc}$ converter) [14]. Therefore, the cell voltage takes the form:

$$
\begin{aligned}
& U_{\text {cell }}=E+\eta_{\text {act }}+\eta_{\text {okmic }} \\
& U_{\text {temp }}=U_{\text {low }}+\left(U_{\text {high }}-U_{\text {low }}\right) \cdot \frac{T_{f c}-T_{\text {low }}}{T_{\text {high }}-T_{\text {low }}}
\end{aligned}
$$

The current for the high and the low temperature curve is calculated from this equation. To find the current at the working temperature of the fuel cell, the current is calculated by linear interpolation:

$$
I_{\text {temp }}=I_{\text {low }}+\left(I_{\text {hich }}-I_{\text {low }}\right) \cdot \frac{T_{f c}-T_{\text {low }}}{T_{\text {high }}-T_{\text {low }}}
$$

where:

$$
\begin{array}{ll}
\mathrm{E} & \text { Thermodynamic potential } \\
\mathrm{I}_{\text {high }} & \text { Maximal current for high temp I-V curve } \\
\mathrm{I}_{\text {low }} & \text { Maximal current for low temp I-V curve } \\
\mathrm{I}_{\text {temp }} & \text { Maximal current at the given temperature } \\
\mathrm{U}_{\text {low }} & \text { Maximal current for low temp I-V curve } \\
\mathrm{U}_{\text {high }} & \text { Maximal current for high temp I-V curve } \\
\mathrm{U}_{\text {temp }} & \text { Maximal voltage at the given temperature } \\
\mathrm{T}_{\mathrm{fc}} & \text { Temperature of fuel cell } \\
\mathrm{T}_{\text {high }} & \text { Temperature for high temp I-V curve } \\
\mathrm{T}_{\text {low }} & \text { Temperature for low temp I-V curve } \\
\eta_{\text {act }} & \text { Anode and cathode activation over-voltage } \\
\eta_{\text {okmic }} & \text { Ohmic over-voltage }
\end{array}
$$

\subsubsection{Electrolyzer Model}

The electrolyzer splits water into hydrogen and oxygen gas. The component subroutine models an alkaline electrolyzer and includes the effects of hydrogen losses and current losses. The electrolyzer is described by two $\mathrm{I}-\mathrm{V}$ curves, one for low temperature and one for a high temperature. It is also necessary to give a maximal operating temperature for the electrolyzer when cooling has to occur to prevent overheating. There are two modes 
for the electrolyzer that gives the opportunity to either give the current as input or the voltage. This mode can be switched during the simulation (the mode is an input) and as this might help to get convergence [15]. Fig. 2 shows the type 160 advanced alkaline electrolyzer used in this simulation.

$$
U_{\text {cell }}=U_{\text {rev }}+\gamma \cdot \frac{I_{\text {ely }}}{A}+S \cdot \log \left[\frac{t \cdot l_{\text {ely }}}{A}+1\right]
$$

where:

A Surface area of electrolyzer

$\mathrm{U}_{\text {cell }} \quad$ Voltage over one electrolyzer cell

$\mathrm{U}_{\text {rev }}$ Reversible voltage

Uely Total voltage over all electrolyzer cells

Iely Current through the electrolyzer cell

$\mathrm{s}, \mathrm{t}$ Constant parameters

$\Upsilon$ Parameter related to ohmic resistance of electrolyte

The Faraday efficiency $\eta_{f}$ is the ratio between the real and theoretical maximum amount of hydrogen produced by the electrolyzer. As increase in temperature leads to a lower electrical resistance, more parasitic current losses and lower Faraday efficiencies occur. The following empirical expression describes these phenomena for a given temperature:

$$
\eta_{f}=\left(\frac{I_{\text {density }}^{2}}{a_{1}+I_{\text {density }}}\right) \times a_{2}
$$

Where $I_{\text {density }}$ is the current density, $a_{1}$ and $a_{2}$ are empirical parameters.

According to Faraday's law, the production rate of hydrogen in an electrolyzer cell is proportional to the electrical current. The total hydrogen production rate $\dot{n}_{H 2}(\mathrm{~mol} \mathrm{~s}-1)$ in an electrolyzer is:

$$
\dot{n}_{H 2}=\eta_{f} \times N_{\text {cell }} \times \frac{I}{n \times F}
$$

Where:

$$
\begin{array}{ll}
\eta_{f} & \text { Faraday efficiency } \\
\text { I } & \text { current through the cell }
\end{array}
$$
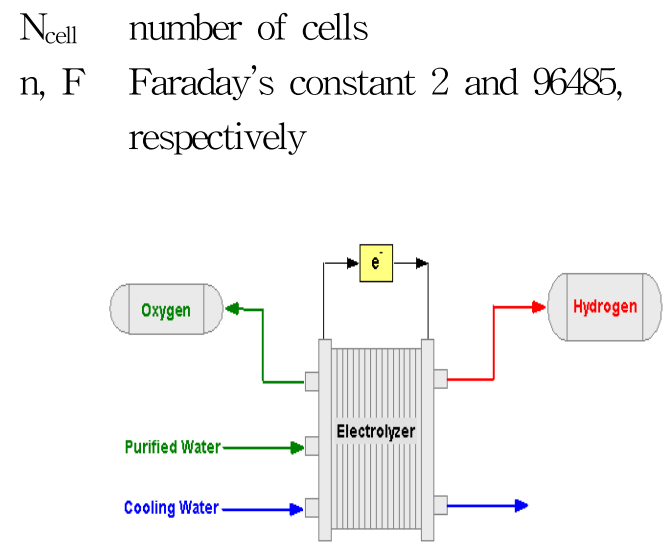

Fig. 2. Type 160 advanced alkaline electrolyzer

\subsubsection{Hydrogen Storage Tank Model}

There are several possibilities for storing hydrogen. The main difficulties with storing hydrogen are its low density and its low boiling point even at high pressure. One method to reduce the volume is to pressurize the electrolyzer, or otherwise to compress the hydrogen.

An electrolyzer can be pressurized up to about 30 bars, while higher pressures in the storage tank require additional hydrogen compression. These compressors require electricity and will increase the parasitic loads to the system [16]. The selected pressure in the storage tank in this study is 40 bars. The equation of state is either the ideal gas or the Van-der-Waal equation of state for real gases. The Hydrogen Storage initial state of charge can be set by the user.

According to the Van Der Waals equation of state, the pressure $\rho$ of a real gas in a storage tank can be calculated from [14] as follows:

$$
\begin{array}{ll}
P=\frac{n \cdot R \cdot T_{\text {gas }}}{V_{\text {ol }}-n \cdot b}-a \cdot \frac{n^{2}}{V_{\text {ol }}^{2}} \\
\mathrm{n} & \text { Number of moles of gas } \\
\mathrm{R} & \text { Universal gas constant } \\
\mathrm{V}_{\text {ol }} & \text { Volume of the storage tank } \\
\mathrm{T}_{\text {gas }} & \text { Temperature of the gas }
\end{array}
$$

a Constant account for the intermolecular 
attraction forces

b Constant account for the volume occupied by the gas molecules

\subsubsection{Controller}

The user can set 4 control variables in the controller. The control logic uses thresholds: when the storage is almost empty, the electrolyzer is switched ON to produce hydrogen and the fuel cell is switched OFF [17]. When the storage state of charge raises above a given threshold, the fuel cell is started to produce electricity (another threshold is used to switch the electrolyzer OFF). The 4 thresholds that the user can control are given as "State Of Charge" levels (0 means empty, 1 is full):

- SOC below which the Electrolyzer is started

- SOC above which the Electrolyzer is stopped

- SOC above which the Fuel Cell is switched ON

- SOC below which the Fuel Cell is turned OFF

\subsubsection{Inverter/Converter Model}

The power loss for rectifier/inverter modes is calculated as follows [14]:

$$
P_{\text {loss }}=P_{\text {in }}-P_{\text {out }}=P_{o}+\left(\frac{U_{s}}{U_{\text {out }}}\right) P_{\text {out }}+\left(\frac{R_{\text {ipn }}}{U_{\text {out }}^{2}}\right) P_{\text {out }}
$$

where:

$$
\begin{aligned}
& \text { Po Idling power (power loss) } \\
& \mathrm{R}_{\mathrm{ipn}} \text { Internal resistance } \\
& \mathrm{U}_{\mathrm{S}} \quad \text { Set point voltage } \\
& \mathrm{P}_{\text {in, }}, \mathrm{P}_{\text {out }} \text { Power input and output }
\end{aligned}
$$

The rectifier/inverter can have either output or input power as input for the calculations (output if the system is connected to a load or input if the system is connected to the electric power net). The rectifier/inverter is disconnected when the input voltage, output voltage or power is zero [18]. The current output is:

$$
I_{\text {ovt }}=\frac{P_{\text {out }}}{U_{\text {out }}}
$$

\subsubsection{Metrological data analysis}

To evaluate the practical model in the TRNSYS program, the surrounding environment and ever-changing weather conditions are entered after accurate management of these data. The metrological data used in this paper were processed to the weather file format of the TRNSYS 16 tool. The components of its metrological file consist of outdoor temperature, direct and diffuse solar radiation, wind direction and speed, relative humidity, and wet bulb temperature. Fig. 3 shows the averaged metrological data processed to the 30 year period of the Daejeon area for the weather input data of Fig. 1[19].

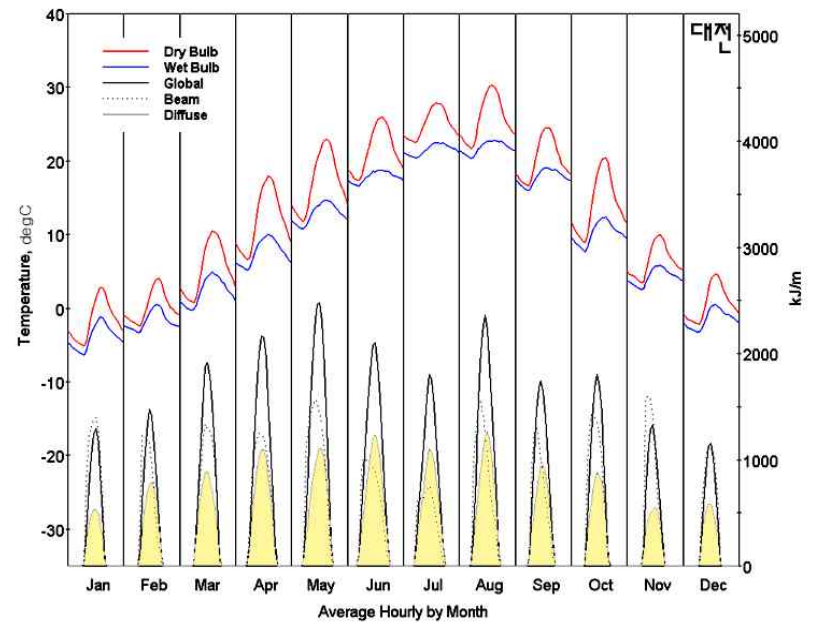

Fig. 3. The averaged metrological data of a 30 year period in Deajeon area (dry bulb and wet bulb temperature, direct and diffuse solar radiation)

\section{Simulation results}

The outputs are mainly of the energy outputs of the components. The simulations can easily be changed to obtain the efficiencies, the voltage, the 
temperatures, the current and a few other variables that are not in the demonstration program due to the enormous amount of possible outputs. This could, however, easily be added into or changed in the program. The outputs are the summary of the energy outputs over the simulation period. With the release of version 16.0, TRNSYS includes a set of hydrogen power system components: PEM fuel cells, a battery bank, an engine generator set, an alkaline electrolyzer, a hydrogen gas compressor With these new components comes the new challenge of system dispatching. When a system is comprised of variously renewable power sources, fuel cells, power generators, batteries and various loads (end use electric loads, hydrogen fuelling loads), it is of critical importance to decide when loads should be met directly by RES, when the battery should be charged or discharged. The overall target of this study is the development of a hybrid system of which the conventional part is replaced by an innovative package using hydrogen as a fuel and which can be considered a zero emission system. Moreover, when considering hybrid systems, operational and replacement costs are mostly coming from the conventional and the battery parts and will not evolve very greatly in the coming years. The use of the so-called innovative components will open new possibilities of future costs decrease both in the investment (a decrease of a factor of 10 to 100 is expected for PEM fuel cells within less than 10 years), operational and replacement point of view (no moving parts, thus less maintenance and the lifetime of the components is expected to be higher) [20]. In the environmental point of view, the replacement of the conventional part of typical hybrid systems by a fuel cell / electrolyser will not only lead to a reduction of air and noise pollution but will also result in the conservation of natural, and a better use of renewable, resources.

\subsection{DEGS simulation results}

Fig. 4 shows the $300 \mathrm{~kW}$ DEGS simulation results with the total waste heat, liquid fuel consumption and total power from the above figure. The DEGS supplies the power to the basic load and alkaline electrolyzer for producing hydrogen, respectively. When PV panel power is insufficient or its hydrogen tank storage is below SOC, DEGS supplies the power to the electrolyzer to produce the hydrogen. To increase the total efficiency of this DEGS, the effective use of waste heat should be considered from a view point of the total energy of the store building. The thermal section was not considered in this study. These simulation results show that the DEGS power has a maximum output of $1750 \mathrm{~kW}$ and also a maximum fuel consumption rate because of comparatively low radiation.

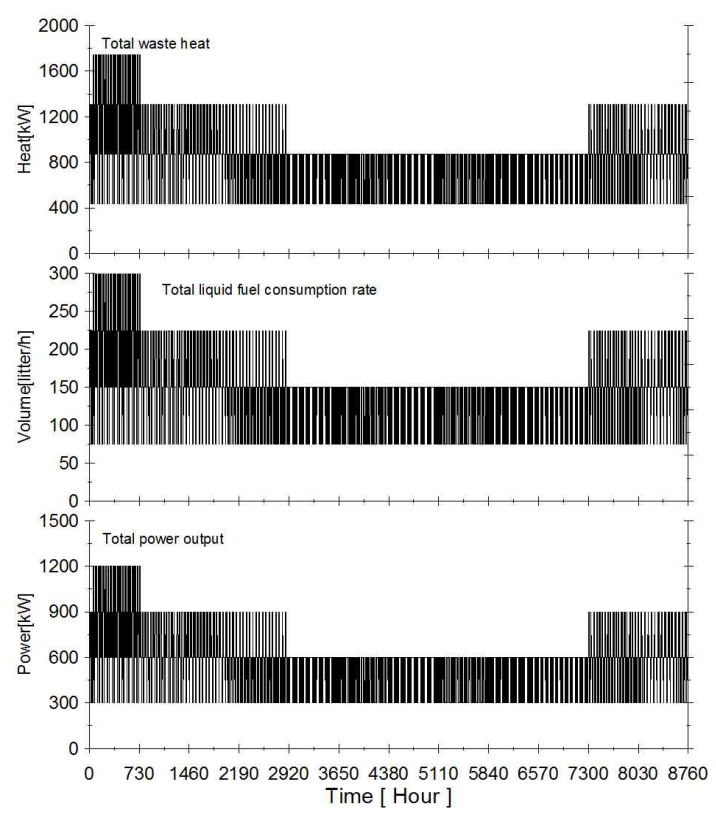

Fig. 4. Total heat, fuel consumption and total power of DEGS 


\subsection{Alkaline electrolyzer simulation results}

The alkaline electrolyzers use an aqueous $\mathrm{KOH}$ solution as an electrolyte. It is best suited for stationary applications that are operating at pressure up to 25 bar.

Since hydrogen has a low energy density, it must be compressed to a very high pressure for storage of a sufficient amount of hydrogen, particularly for mobile applications. Added to this, hydrogen cannot be considered an ideal gas for pressures above 15 MPa. Alkaline electrolyzers have been around commercially for a long time to produce hydrogen from the splitting of water and electrochemical process, which involve the use of electricity to split water into its components, e.g. hydrogen and oxygen. In this study an alkaline electrolyzer was chosen, which required an electrical power of $100 \mathrm{~kW}-430 \mathrm{~kW}$, as shown in Fig. 5 (total power
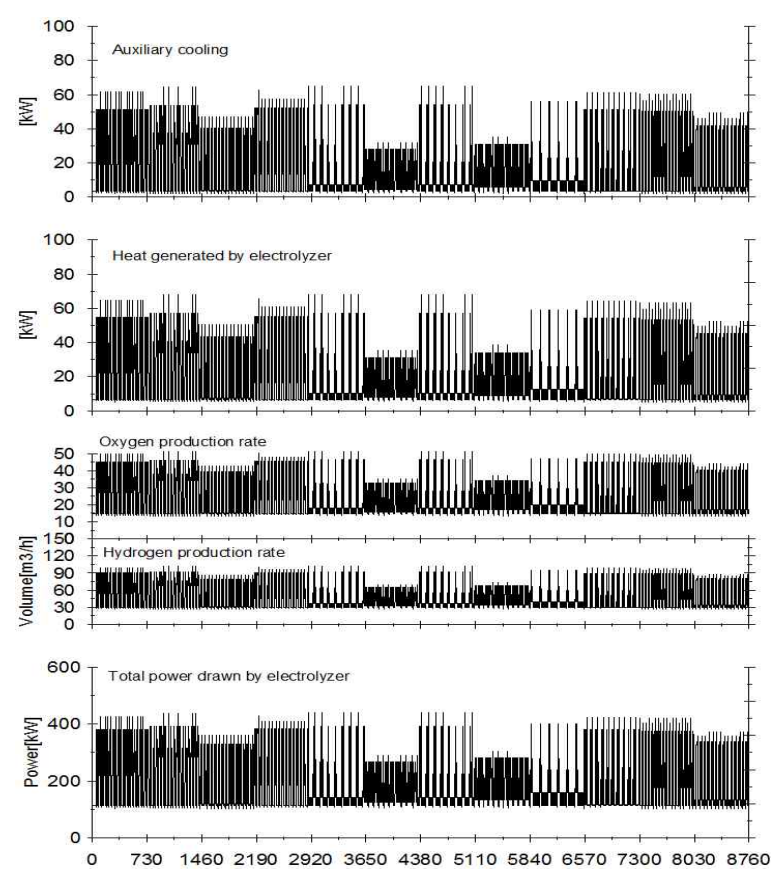

Fig. 5. Electrolyzer simulation results drawn by electrolyzer) This alkaline electrolyzer produces hydrogen at $30-90 \mathrm{~m}^{3} / \mathrm{h}$ and oxygen at $15-45 \mathrm{~m}^{3} / \mathrm{h}$. Because heat is generated for operating a water electrolyzer, a $63 \mathrm{~kW}$ auxiliary cooling system is needed to cool the electrolyzer system. The generated hydrogen is conveyed to the hydrogen storage tank to supply the hydrogen to the PEMFC. Fig. 6 shows the simulation results of auxiliary cooling power, heat generated by the electrolyzer, oxygen production rate, hydrogen production rate, and total power drawn by the electrolyzer from the upper figure.

\subsection{FC simulation results}

Fig. 6 shows that total power output amounts to 60-300kW hourly to form the lower figure. Simultaneously, the FC generated the thermal heating for operating the electrochemical reaction. Total heating capacity is $45-350 \mathrm{~kW}$ per hour. To increase the total efficiency of $\mathrm{FC}$, an effective way

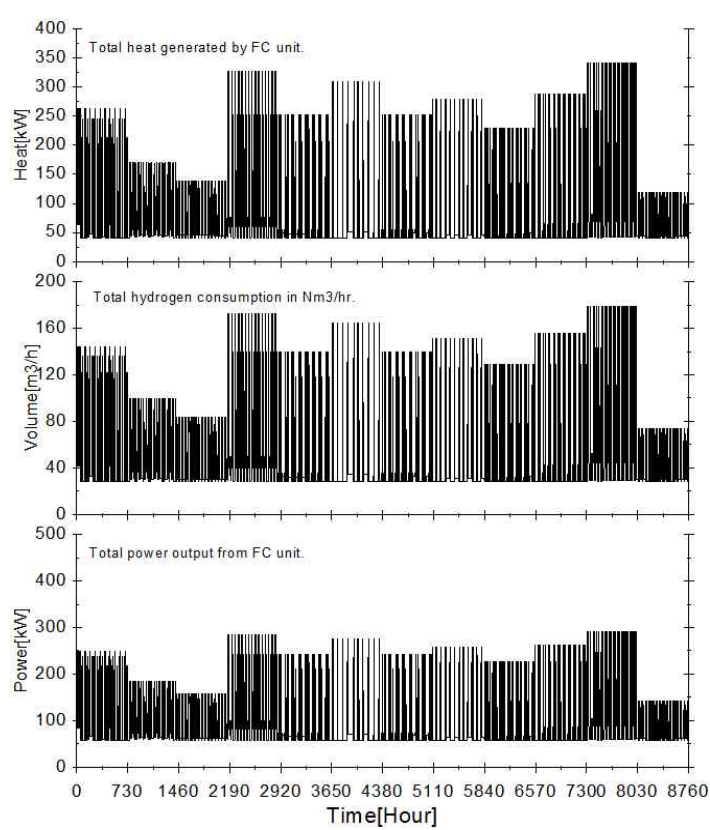

Fig. 6. FC simulation results 
of heating utilization is required for space heating and heating water. Economically. because the quantity of hydrogen produced by the electrolyzer is greater than that consumed by $\mathrm{FC}$, the optimal sizing of hydrogen hybrid energy system and the possibility of various FCs utilization should be investigated in various aspects.

\subsection{Total evaluation results of Solar/FC/DEGS system}

Fig. 7 shows the energy balance between the generating power of the solar/FC/ DEGS energy system and the dominant ventilation load for $\mathrm{L}$ store. The solar/FC/ DEGS energy system generates a total power of 2,730MWh. Thus, the PV panel, DEGS and PEMFC produce the power of 0.956MWh, 1,937MWh and 792.1MWh, respectively. A comparatively small portion of PV power is due to the cause of installation limits in the roofs and facades of $\mathrm{L}$ store. The design for large power generation via PV panels is a very important element in the economical stand-alone operation of a hydrogen energy system. Consuming electric energy for ventilation load in $\mathrm{L}$ store amounts to 2781MWh for one year, which comprises the ventilation load of 1,129MWh and energy consumed by the electrolyzer of 1,651MWh. The diminutive energy difference between the generating power of a solar/FC/ DEGS energy system and the dominant ventilation load for $\mathrm{L}$ store is estimated as system model nonlinearity and simulation truncation error. Therefore, the effectiveness and comparative accuracy of a hybrid energy system and controller model are verified from the simulation results. Also, the developed model system and its control strategy exhibit excellent performance for simulations of a long period of time (8,760 hours). Simulation results represent a good performance of energy balance because of the use of variable speed control of DEGS. The simulation results as shown in Fig. 9 are illustrated from the figure of the $\mathrm{FC}$ total power output, total power drawn from the electrolyzer, total power output of the PV array, diesel engine power and finally the demand load of ventilation.
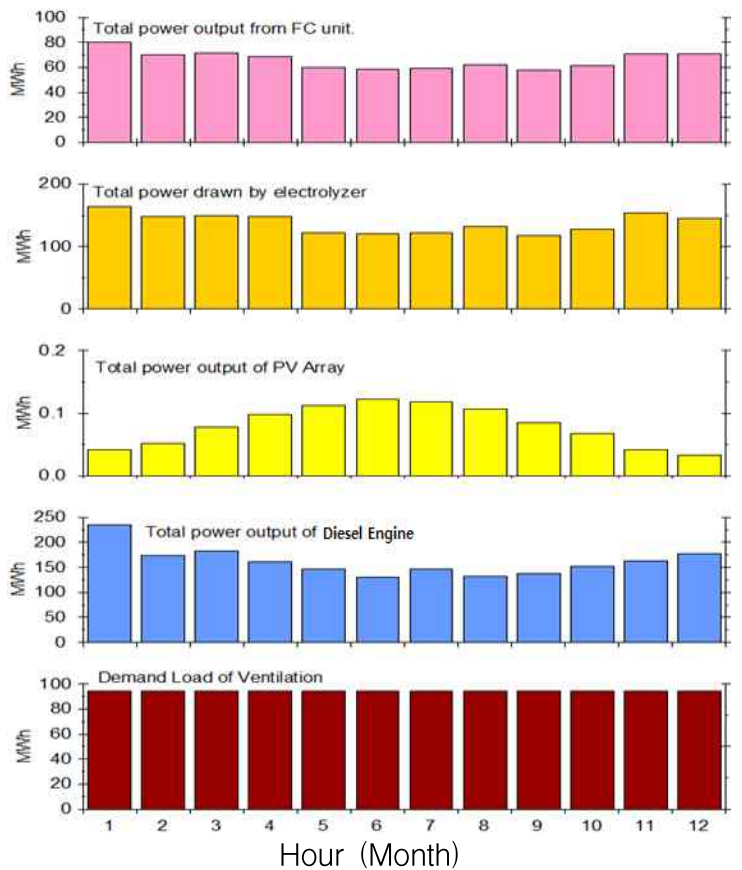

Fig. 7. Simulation results of total energy balance

\section{Conclusions}

The application of integrated hydrogen technology has illustrated the potential of a fuel cell and hydrogen storage system for electricity from wind and photovoltaic hydropower energy in a stand-alone system. With this analysis, a new concept for designing a renewable power system by using an integrated hydrogen renewable energy system was proposed. In comparison to conventional 
renewable energy system designs, the results from the study indicate that replacing a diesel engine and battery system with a hydrogen fuel cell system can provide significant fuel savings and reliable operation with energy balance with a reduction of dumped energy.

Furthermore, the research will address the new options concerning the impact of integrated renewable energy systems, which will be made by reducing or replacing the existing diesel and battery system based on the solar-fuel cell system.

The diminutive energy difference between the generating power of the solar/FC/ DEGS energy system and the dominant ventilation load for $\mathrm{L}$ store is estimated as system model nonlinearity and simulation truncation error. Therefore, the effectiveness and comparative accuracy of a hybrid energy system and controller model are verified from the simulation results. Also, the developed model system and its control strategy exhibit excellent performance for a simulation over a long period of time (8,760 hours). Simulation results show a good performance of energy balance because of the use of variable speed control of DEGS. The economical evaluation of this hydrogen energy system will be carried out in accordance with various conditions in the future.

\section{Acknowledgements}

This research was supported by the research fund of Hanbat National University and the KETEP under Grant 2013T100200078.

\section{References}

[1] Lund H, Mathiesen BV, "Energy system analysis of 100\% renewable energy systems-the case of Denmark in years
2030 and 2050", Energy 2009;34:524e31.

[2] Schucan T, "Case Studies of Integrated Hydrogen Energy Systems", Report, IEA/H2/T11/RR1-2000, International Energy Agency Hydrogen Implementing Agreement Task 11. Integrated Systems Operating agent: National Renewable Energy Laboratory, Golden, Colorado, 1999.

[3] W.P. Hong, "Power control and modeling of solar-hydrogen hybrid energy system for stand-alone applications in building", 16th International Conference on Electrical Engineering, July 11-14, 2010 Busan Korea.

[4] R.W. Wies, R.A. Johnson, A.N. Agrawal, T.J. Chubb, Simulink model for economic analysis and environmental impacts of a PV with diesel-battery system for remote villages, IIEETrans. Power Syst. 20 (2) (2005) 692 - 700.

[5] E.S. Abdin, A.M. Osheiba, M.M. Khater, Modeling and optimal controllers design for a stand-alone photovoltaic-diesel generator unit, IEE Trans. Energy Conver. 14 (3) (1999) $560-565$.

[6] H.S. Ko, T. Niimura, K.Y. Lee, An intelligent controller for a remote wind-diesel power system-design and dynamic performance analysis, in: IEIE PES, 2003, pp. $2147-2152$.

[7] Ulleberg, $\varnothing$. and Pryor T.L., Optimization of Integrated Renewable Energy Hydrogen Systems in Diesel Engine Mini-Grids. WIEC 2002 - 14th World Hydrogen Energy Conference, Montreal, 9-14 June 2002.

[8] Federal Energy Technology Center Fuel Cells - Opening new frontiers in power generation, US Department of Energy, Office of Fossil Energies, Federal Energy Technology Center, Morgatown, USA, 2000.

[9] E.I. Zoulias, "Hydrogen-based Autonomous Power System", 2008 Springer.

[10] Won-Pyo Hong, "The Energy Performance Analysis of Large Scale Store Using Dynamic Thermal Analysis Simulation Program", Joumal of The Korean Solar Energy Society, Vol. 30, No. 6, pp. 44-49, 2011.

[11] Ulleberg O, "Stand-alone power systems for the future: optimal design, operation and control of solar hydrogen energy system", ph.D dissertation, Norwegian University of Science and Technology, 1998.

[12] T.E., Zawodzinski, T.A. and Gottesfeld, S., Polymer Electrolyte Fuel Cell Model, Joumal of Electrochemical Society, vol.138, no.8, pp.2334-2342, 1991, Springer.

[13] John L. S., Liquid Hydrogen As A Propulsion Fuel, The NASA History Series, Scientific and Technical Information Office, National Aeronautics and Space Administration, Washington, D.C., 1978.

[14] TRVSYS 16 User Manual Volume 5 Mathematical Reference, Solar Energy Laboratory, University of Wisconsin-Madison, 2004.

[15] Lehman, P. A. Chamberlin, C. E., Pauletto, G.and Rocheleau, M. A., Operating Experience with A Photovoltaic-Hydrogen Energy System, Published in the proceedings of: Hydrogen '94: The 10th World Hydrogen Energy Conference Cocoa Beach, Florida, June 20-24, 1994. 
[16] Ding, J.J and Buckeridge, J.S., Design Considerations for a Sustainable Hybrid Energy System, IPENZ Transactions, 2000, Vol. 27, No.1, EMCh, 2000.

[17] Federal Energy Technology Center Fuel Cells Opening new frontiers in power generation, US Department of Energy, Office of Fossil Energies, Federal Energy Technology Center, Morgantown, USA, 2000.

[18] Jennings, W. and Green, J., Optimization of Electric Power Systems for Off-Grid Domestic Applications: an Argument for Wind/Photovoltaic Hybrids, U.S. Department of Energy Undergraduate Research Journal, 2002.

[19] Byung-Soo Kim, Won-Pyo Hong, Young-Wok Gil, "The Energy Performance \& Economy Efficiency Evaluation Mictoturbine Installed Hospital Building", Journal of KIEI, Vol. 23, No. 12, pp. 176-183, 2009.

[20] Altmann, M., Niebauer, P., Pschorr-Schoberer, E. and Zittel, W., Wind-Hydrogen Supply of Electricity Markets - Technology - Economics, Wind Power for the 21st Century, Kassel, Germany, 25-27 September 2000.

\section{Biography}

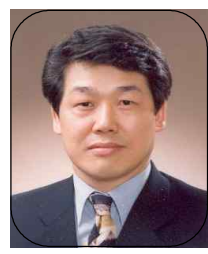

\section{Won-Pyo Hong}

Won-Pyo Hong received a B.S. degree in Electrical Engineering from Sungsil University, Seoul, Korea, in 1978 and M.Sc. and Ph.D. degrees in Electrical Engineering from Seoul National University, Seoul, Korea, in 1980 and 1989, respectively. From 1980 to 1993, he was senior researcher of the Korea Electric Power Research Institute at the Korea Electric Power Cooperation. He was visiting professor at the UBC, Canada, from 2007 to 2008. He is a professor in the Department of Building Services and Plant Engineering of Hanbat National University, where he has taught since 1993. His main research interests are building energy and management systems, smart green buildings, fieldbus bus-based control and distributed energy resources. 